\title{
The Arabidopsis thaliana DNA-Binding Protein AHL19 Mediates Verticillium Wilt Resistance
}

\author{
Koste A. Yadeta, ${ }^{1}$ Mathieu Hanemian, ${ }^{2}$ Patrick Smit, ${ }^{1}$ Jelle A. Hiemstra, ${ }^{3}$ Andy Pereira, ${ }^{4}$ Yves Marco, ${ }^{2}$ \\ and Bart P. H. J. Thomma ${ }^{1}$

\begin{abstract}
${ }^{1}$ Laboratory of Phytopathology, Wageningen University, Droevendaalsesteeg 1, 6708 PB Wageningen, The Netherlands; ${ }^{2}$ Laboratoire des Interactions Plantes Microorganismes, Unité Mixte de Recherche, Centre National de la Recherche Scientifique-Institut National de la Recherche Agronomique 2594/441, F-31320 Castanet-Tolosan, France; ${ }^{3}$ Applied Plant Research, Wageningen University and Research Centre, P.O. Box 85, 2160AB Lisse, The Netherlands; ${ }^{4}$ Virginia Bioinformatics Institute, Virginia Tech, Blacksburg 24061, U.S.A.
\end{abstract}

Submitted 12 April 2011. Accepted 16 August 2011.

Verticillium spp. are destructive soilborne fungal pathogens that cause vascular wilt diseases in a wide range of plant species. Verticillium wilts are particularly notorious, and genetic resistance in crop plants is the most favorable means of disease control. In a gain-of-function screen using an activation-tagged Arabidopsis mutant collection, we identified four mutants, A1 to A4, which displayed enhanced resistance toward the vascular wilt species Verticillium dahliae, V. albo-atrum and V. longisporum but not to Fusarium oxysporum f. sp. raphani. Further testing revealed that mutant A2 displayed enhanced Ralstonia solanacearum resistance, while mutants A1 and A3 were more susceptible toward Pseudomonas syringae pv. tomato. Identification of the activation tag insertion site in the $\mathrm{A} 1$ mutant revealed an insertion in close proximity to the gene encoding AHL19, which was constitutively expressed in the mutant. AHL19 knock-out alleles were found to display enhanced Verticillium susceptibility whereas overexpression of $A H L 19$ resulted in enhanced Verticillium resistance, showing that AHL19 acts as a positive regulator of plant defense.

Verticillium spp. belong to the most destructive soilborne fungal pathogens and cause vascular wilt disease in a wide range of plant species, including annual crops, vegetables, fruits, fiber crops, and perennial woody plants (Fradin and Thomma 2006; Klosterman et al. 2009, 2011). Verticillium wilt diseases cause huge economic losses in most, if not all, agroecological regions worldwide. While Verticillium dahliae and V. albo-atrum are closely related, truly plant pathogenic, and cover a wide host range of over 200 dicotyledonous plant species, $V$. longisporum causes disease on Brassicaceous plants only (Fradin and Thomma 2006; Klosterman et al. 2011). Verticillium wilts are particularly notorious because control of these diseases is extremely difficult for a number of reasons: i) the resting structures can survive in soil in the absence of host plants for up to 15 years (Wilhelm 1955), ii) soil fumigation is expensive and has harmful environmental effects (Rowe et al. 1987), iii) the fungi have broad host ranges which makes crop rotation ineffective, and iv) the pathogens cannot be reached

Corresponding author: B. P. H. J. Thomma; E-mail: bart.thomma@wur.nl

* The $\boldsymbol{e}$-Xtra logo stands for "electronic extra" and indicates that fifteen supplementary figures and one supplementary table are published online and that Figures 1, 2, 3, and 5 appear in color online. by many fungicides once they have entered the vascular system of host plants, and only few fungicides exist to cure infected plants. Therefore, genetic resistance in crop plants is the most favorable means to control Verticillium wilt diseases (Fradin and Thomma 2006).

Genetic resistance against Verticillium wilt diseases has been reported for several economically important crop species (Fradin and Thomma 2006; Klosterman et al. 2009). However, thus far, the only locus that has been cloned and functionally characterized is the tomato Ve locus that contains the Vel gene that provides tomato resistance against isolates of the species $V$. dahliae and V. albo-atrum that belong to race 1 (Fradin et al. 2009, 2011; Kawchuk et al. 2001). However, Verticillium race 2 strains are able to overcome $\mathrm{Ve}$-mediated resistance and have become a problem for commercial tomato production (Schaible et al. 1951) and, presently, no resistance against race 2 Verticillium isolates has been described. Single dominant Verticillium resistance genes have been identified in other plant species as well, including potato, cotton, sunflower, and Arabidopsis, while polygenic Verticillium resistance has been reported for strawberry, potato, alfalfa, cotton, oilseed rape, and tomato (Fradin and Thomma 2006; Jiang et al. 2009; Rygulla et al. 2008; Simko et al. 2004). In recent years, Arabidopsis has increasingly been used as a model host for studying wilt diseases caused by $V$. dahliae (Ellendorff et al. 2009; Fradin and Thomma 2006; Fradin et al. 2011; Johansson et al. 2006; Pantelides et al. 2010; Tjamos et al. 2005; Veronese et al. 2003).

In addition to screening germplasm of a plant species or its wild relatives for resistance (Schaible et al. 1951; Veronese et al. 2003), mutagenesis followed by screening for enhanced resistance with the pathogen of interest is a means to identify novel resistance traits. Several technologies have been developed, including ethylmethane sulphonate (EMS)- and radiation-induced mutation, and transposon and activation tagging, each with its own advantages. Activation tagging involves the random integration of promoter or enhancer sequences in a plant genome using either a T-DNA or a transposon, generally leading to enhanced expression of genes near the integration site and generating gain-of-function mutants (Ayliffe and Pryor 2007; Weigel et al. 2000). Transposon-based activation tagging has been successfully used in various plant species to identify novel genes involved in various physiological processes (Ayliffe and Pryor 2007), including pathogen defense (Aboul-Soud et al. 2009; Grant et al. 2003; Xia et al. 2004). To identify genes involved in Verticillium wilt resistance, we 
screened an Arabidopsis transposon-based activation-tagged mutant collection (Marsch-Martinez et al. 2002). Four mutants were identified that displayed enhanced resistance to $V$. dahliae, V. albo-atrum, and V. longisporum. Subsequent analysis of one of the mutants has demonstrated that the specific activation of the gene encoding the AT-hook motif nuclear localized DNA-binding protein AHL19 causes the enhanced resistance phenotype.

\section{RESULTS}

Screening of an Arabidopsis activation-tagged mutant collection for enhanced Verticillium resistance.

In our research, Arabidopsis thaliana is used as host to investigate the biology of Verticillium wilt diseases (Ellendorff et al. 2009; Fradin et al. 2011). To identify Arabidopsis genes that can contribute to resistance against Verticillium wilt, a collection of 2,000 stable transposon activation tag insertion lines in the Arabidopsis ecotype Ws (Marsch-Martinez et al. 2002) was screened for plants displaying enhanced resistance upon inoculation with $V$. dahliae. This resulted in the identification of four mutants, A1 to A4, which displayed fewer symptoms of Verticillium disease (chlorosis, stunting, and wilting) when compared with other mutants in the collection and the corresponding wild-type Ws (Fig. 1A). At 14 days postinoculation (dpi), leaves of wild-type plants showed clear wilting and chlorosis symptoms, whereas these symptoms were absent from leaves of the four mutants. By $21 \mathrm{dpi}$, wild-type plants were severely stunted while the oldest rosette leaves displayed chlorosis and severe necrosis. Whereas A3 and A4 mutant plants showed only slight symptoms of disease, A1 and A2 mutant plants remained symptomless. With real-time polymerase chain reaction (PCR) on genomic DNA as the target for quantification (Ellendorff et al. 2009), significantly less Verticillium DNA (using the internal transcribed spacer region of the ribosomal DNA as a marker) normalized to the amount of host DNA (using the RuBisCo gene as a marker) was detected in the four mutants when compared with wild-type plants at both time points (Fig. 1B), confirming that the four mutants display enhanced $V$. dahliae resistance.

As with $V$. dahliae, all mutants showed enhanced resistance to $V$. albo-atrum and $V$. longisporum when compared with wild-type plants, and real-time PCR quantification of fungal biomass using genomic DNA as target for quantification confirmed reduced colonization of the mutants when compared with wild-type plants for both fungal species (Fig. 1; Supplementary Figs. S1 and S2).

In addition to the absence of disease symptoms, the four mutants showed clear differences in rosette leaf morphology when compared with wild-type plants. Whereas mutant A1 displayed enlarged leaves, delayed flowering, and delayed senescence, mutant A2 displayed compact, rounded rosette leaves with short petioles, mutant A3 had curly leaves with lobbed leaf edges, and mutant A4 had small, thick rosette leaves when compared with wild-type plants (Fig. 1A).

\section{Response of Verticillium spp.-resistant mutants to other vascular wilt pathogens.}

We subsequently studied whether the enhanced resistance of the mutants is specific to Verticillium spp. or extends to other
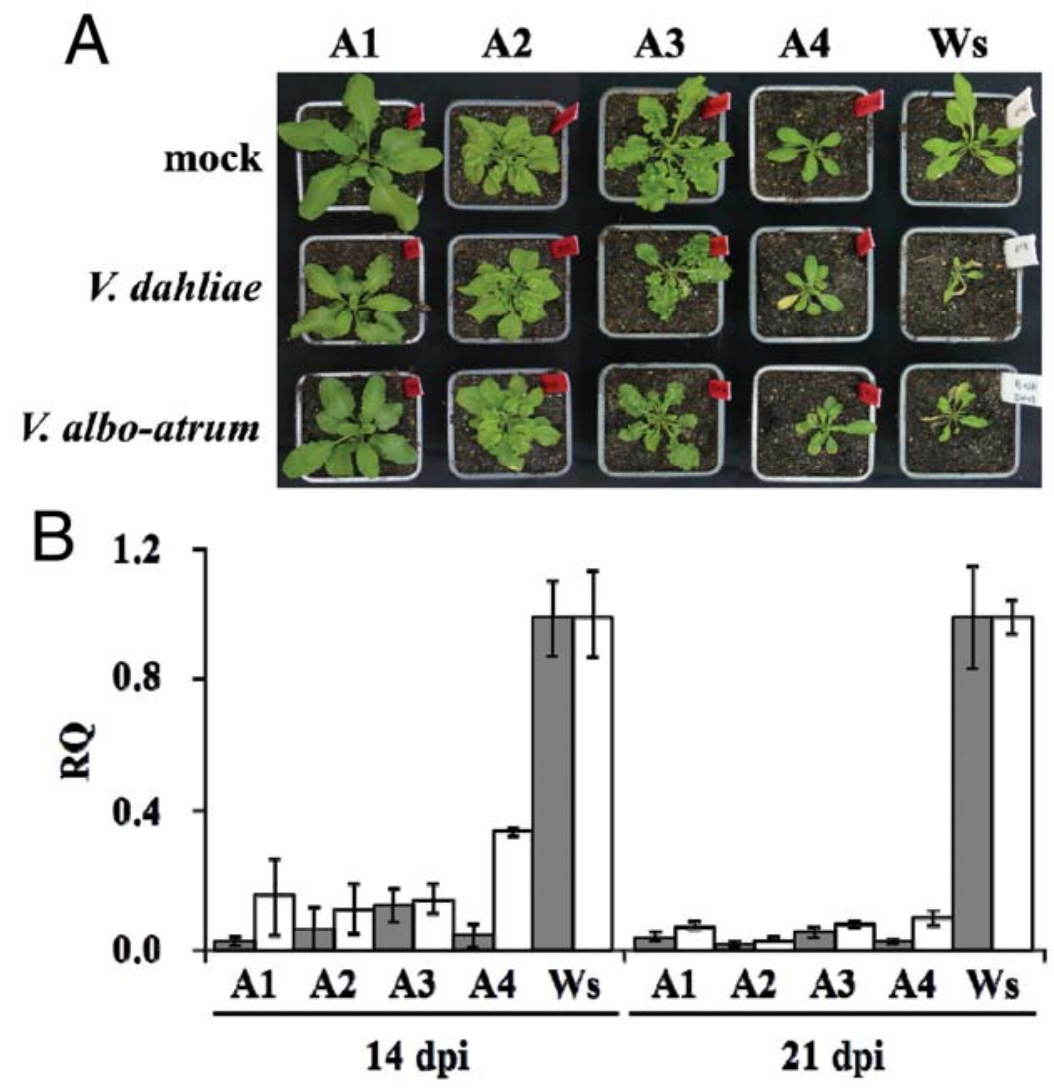

Fig. 1. Activation-tagged Arabidopsis mutants are more resistant to Verticillium spp. A, Typical Verticillium disease symptoms (stunting, wilting, and chlorosis) on wild-type (Ws) and activation-tagged mutants (A1-A4) at 21 days postinoculation (dpi). Upper, middle, and lower rows show mock-, Verticillium dahliae- and V. albo-atrum-inoculated plants, respectively. A representative of three independent experiments is shown. B, Relative quantification (RQ) by real-time polymerase chain reaction on genomic DNA of Verticillium colonization by comparing levels of the V. dahliae (gray bars) and V. albo-atrum (white bars) internal transcribed spacer region of the ribosomal DNA (as measure for fungal biomass) relative to levels of the large subunit of the Arabidopsis RuBisCo gene (for equilibration) at 14 and 21 dpi. Bars represent averages with standard deviation of three independent biological replicates. 
vascular pathogens as well. However, none of the mutants showed enhanced resistance to Fusarium oxysporum f. sp. raphani (Diener and Ausubel 2005, Ellendorff et al. 2009) when compared with wild-type plants (Fig. 2A; Supplementary Fig. S3). However, although mutant A2 showed clearly enhanced resistance toward the bacterial vascular wilt pathogen Ralstonia solanacearum (Genin and Boucher 2002), none of the other mutants showed differential susceptibility when compared with wild-type plants (Fig. 2A and B). Thus, the enhanced Verticillium resistance of the mutants does not generally extend to other vascular pathogens, except for mutant A2 that is also resistant to $R$. solanacearum.

\section{Response of Verticillium spp.-resistant mutants to foliar pathogens.}

In addition to vascular pathogens, three necrotrophic foliar fungal pathogens were tested: Botrytis cinerea, Plectosphaerella cucumerina, and Alternaria brassicicola. For $P$. cucucmerina, leaves of the four mutants and wild-type plants showed clear necrosis at the site of inoculation at $3 \mathrm{dpi}$, which resulted in lesion expansion and tissue collapse by 5 dpi. No significant differences were observed between the wild type and the mutants (Fig. 3). Similar results were obtained for $B$. cinerea and A. brassicicola (Fig. 3), and all results were confirmed by measurements of lesion diameters (Supplementary
Fig. S4). These results showed that the enhanced Verticillium resistance of the mutants cannot be explained by generally enhanced resistance against fungal pathogens.

Subsequently, the response of the mutants to the bacterial pathogen Pseudomonas syringae pv. tomato DC3000 was studied. Whereas the mutants A1, A2, and A4 showed similar disease symptoms when compared with wild-type plants, mutant A3 showed clearly enhanced symptoms of the disease (Fig. 3). At 5 dpi, severe necrosis of leaves of the A3 mutant plants was observed, while wild-type, A1, A2, and A4 plants showed only mild chlorosis and slight necrosis (Fig. 3). In planta, $P$. syringae pv. tomato DC3000 proliferation was assessed using realtime PCR (Brouwer et al. 2003) at 3 and 5 dpi. Although A1 and A3 showed significantly enhanced levels of bacterial colonization at both time points, mutant A4 showed a similar level of colonization when compared with wild-type plants. However, mutant A2 showed significant level of DC3000 colonization at 3 dpi and wild-type colonization at 5 dpi (Supplementary Fig. S5).

\section{Assessment of root development and architecture.}

Verticillium spp. invade their hosts via the root, penetrate the root cortex, and colonize the xylem tissue (Fradin and Thomma 2006). Because the four Verticillium spp.-resistant mutants displayed clear morphological alterations of above-
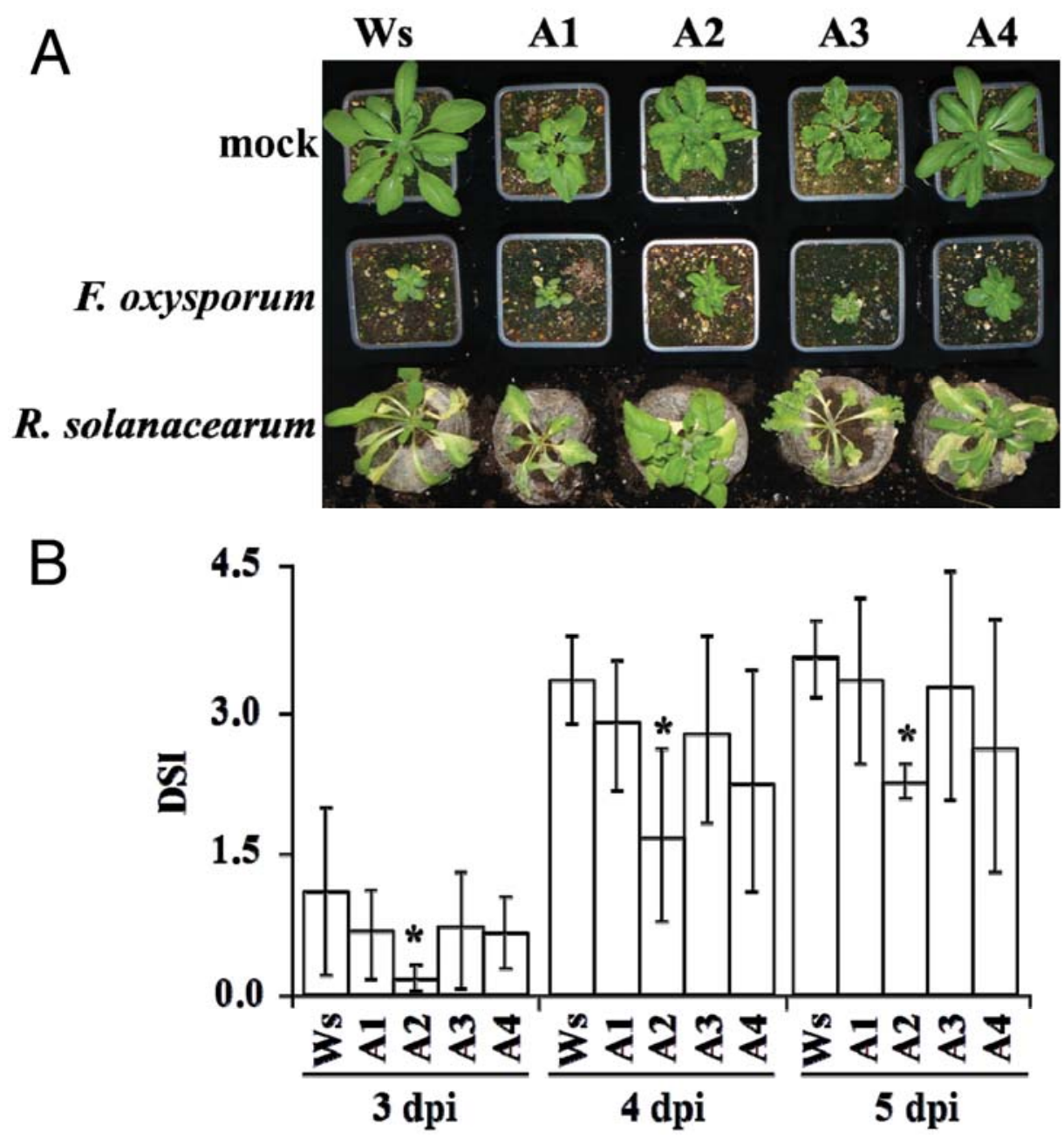

Fig. 2. Response of Verticillium spp.-resistant mutants to other vascular pathogens. A, Typical mock-inoculated wild-type plants (Ws) and activation-tagged mutants (A1-A4) and symptoms caused by Fusarium oxysporum at 12 days postinoculation (dpi) and Ralstonia solanacearum at 5 dpi. A representative of three independent experiments is shown. B, Disease severity index (DSI) scores upon inoculation of at least 21 plants with $R$. solanacearum on a scale of 0 (no infection) to 4 (all rosette leaves diseased) at 3, 4, and 5 dpi. Bars represent averages with standard deviation of three independent biological replicates and the asterisks indicate significant differences $(P<0.05)$. 
ground organs, possibly root morphology could also be affected, explaining the altered Verticillium susceptibility. To investigate this possibility, root growth and architecture of soil-grown seedlings were assessed. Up to 2 weeks postgermination, the time point when Verticillium inoculation is performed, no differences in root development and architecture were observed for any of the mutants when compared with wild-type plants (Fig. 4A). Measurements of root length did not show significant differences between wild-type roots and those of the mutants (Fig. 4B).

Because none of the mutants displayed obvious macroscopic differences in root growth and architecture that can explain the enhanced Verticillium resistance of the mutants, the xylem structure in wild-type and mutant plants was analyzed microscopically. To this end, the wild type and the mutants were grown in vitro. As with soil-grown plants, no significant differences in root development, architecture, or length were monitored up to 2 weeks postgermination (Supplementary Fig. S6). No obvious differences in structure and cellular orientation of xylem elements were observed between the roots of mutants and wildtype plants upon microscopic analysis of toluidine-blue-stained root cross sections (Fig. 4C, upper panels). Furthermore, brightfield analysis of the (longitudinal) axis of living roots revealed no differences in the development and structure of the epidermis, cortex, endodermis, and vasculature cells between the wild type and mutants (Fig. 4C, middle panels). Measurements of the diameters of epidermis, cortex, and endodermis cells also showed no significant differences between the mutant and wildtype roots. Finally, root tips were analyzed with confocal laserscanning microscopy after fixation and staining with propidium iodide (Truernit et al. 2008). Again, no obvious differences between mutants and the wild type were observed (Fig. 4C, bottom panels). Altogether, these data suggest that the enhanced Verticillium resistance of the mutants cannot be explained by macroscopic differences in root development or architecture.

\section{Determination of the activation tag insertion site in mutant $\mathrm{A} 1$.}

Due to the enhanced resistance phenotype which exclusively concerned Verticillium spp., mutant A1 was selected for further molecular characterization of the enhanced resistance phenotype. The activation tag insertion site was cloned using thermal asymmetric interlaced PCR (TAIL-PCR) (Liu and Whittier 1995) and the flanking sequence was determined. BLAST analysis of the flanking sequence using the Arabidopsis genome sequence revealed that the activation tag was inserted in chromosome 3,81 bp upstream of the predicted translational start codon of the At3g04570 gene which encodes the AT-hook DNA-binding protein AHL19 (Fujimoto et al. 2004) (Supplementary Fig. S7). The position of the insertion site was confirmed by PCR amplification and subsequent sequencing of the chromosomal region flanking the activation tag insertion site in the A1 mutant. Several of the genes $10 \mathrm{~kb}$ downstream and $20 \mathrm{~kb}$ upstream of the activation tag insertion site (Table 1) encode proteins that have previously been implicated in pathogen defense, such as defensin-like proteins (At3g04540 and At3g04545) (Thomma et al. 2002) and the ethylene receptor EIN4 (At3g04580) (Johansson et al. 2006). Furthermore, several genes encoding transcription factors surround the activation tag insertion site (At3g04590, At3g04610, and At3g04620).

Subsequently, the expression of genes flanking the insertion site was compared between the A1 mutant and wild-type plants in the absence of pathogen inoculation. Reverse-transcription PCR showed a strong induction of gene At3g04570 (AHL19) in mutant A1 when compared with wild-type plants (Supplementary Fig. S8). Furthermore, the At3G04530 gene appeared to be slightly induced while the At3G04580, At3G04605, and At3G04630 genes were repressed in the mutant when compared with the wild type. The transcript levels of all other genes were similar in mutant A1 and the wild type. These results suggest that activation of gene AHL19 may be causal to the enhanced

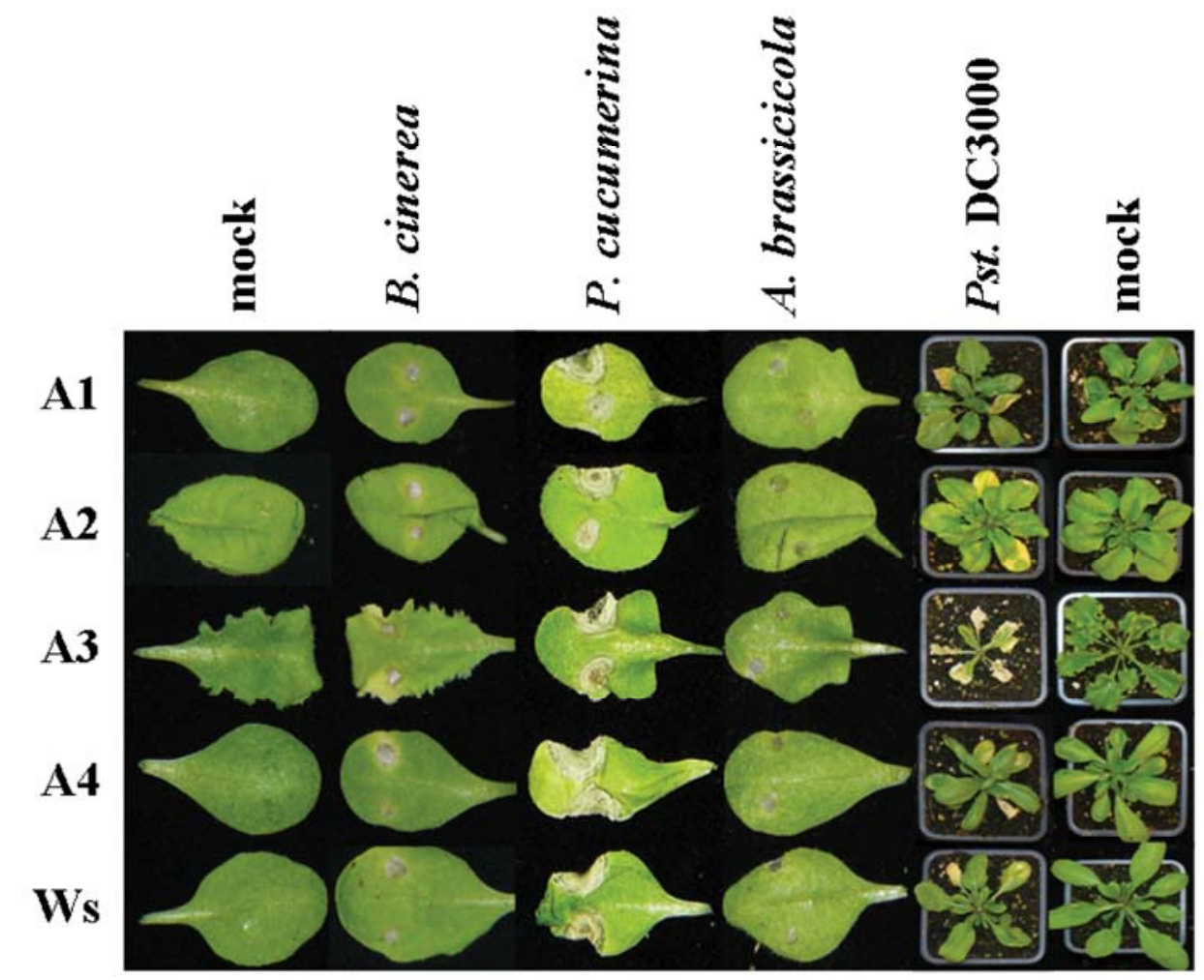

Fig. 3. Response of Verticillium spp.-resistant mutants to foliar pathogens. Typical disease symptoms caused by the necrotrophic fungal pathogens Botrytis cinerea, Plectosphaerella cucumerina, Alternaria brassicicola, and Pseudomonas syringae pv. tomato strain DC3000 on the activation-tagged mutants A1 to A4 and the wild-type Ws at 5 days postinoculation. A representative of three independent experiments is shown. 
Verticillium resistance phenotype, because expression of this gene is most significantly induced in the A1 mutant.

Homozygous knock-out alleles of all genes flanking the activation tag insertion site in mutant A1 were tested for their level of Verticillium susceptibility (Table 1). Because the vast majority of publicly available knock-out alleles is in the Col-0 ecotype while the A1 mutant is in Ws, the susceptibility of plants of the Col-0 and Ws ecotypes were compared, revealing that plants of the Col-0 ecotype are less susceptible to $V$. dahliae infection than Ws plants. The analysis of the knockout alleles in Col-0 showed that only the insertion in AHL19 (ahl19-1) displayed significantly enhanced V. dahliae susceptibility while all other lines displayed wild-type susceptibility levels (Table 1) (Supplementary Fig. S9).
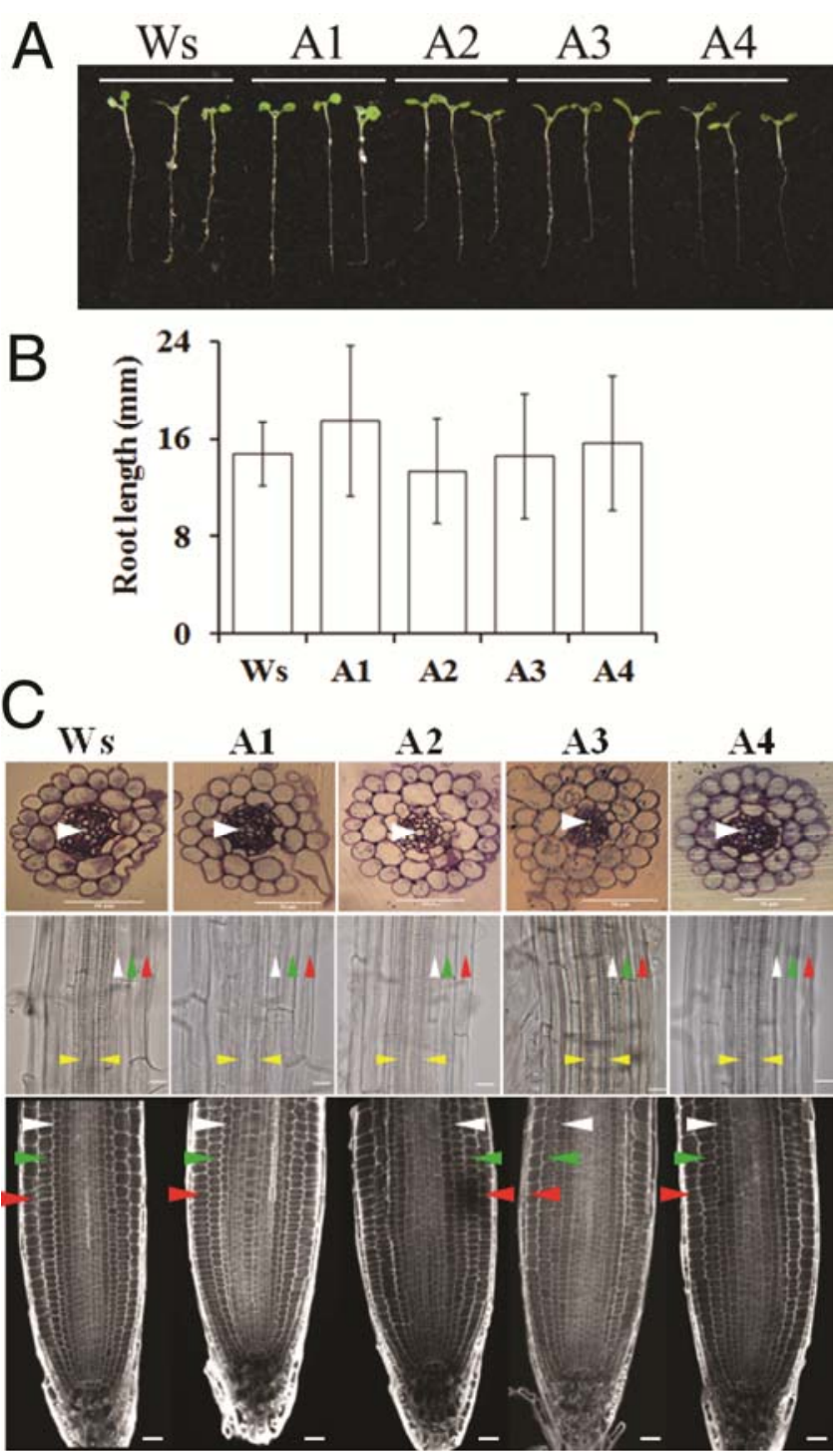

Fig. 4. Root development and architecture of Verticillium spp.-resistant mutants. A, Typical appearance of 12-day-old roots of soil-grown activation-tagged mutants (A1-A4) and wild-type (Ws) plants. B, Primary root length of 12-day-old soil-grown wild-type (Ws) plants and activationtagged mutants (A1-A4). C, Microscopic analysis of roots of 12-day-old in-vitro-grown wild-type (Ws) and mutant (A1-A4) plants showing the epidermal (red arrow), cortical (green arrow), endodermal (white arrow), and vascular bundle (yellow arrow) cells. The upper panel shows root xylem elements (white arrow) in a cross section after staining with toluidine blue; the middle panel shows a bright-field image of the epidermal, cortical, endodermal, and vascular bundle cells; and the bottom panel shows a confocal laser-scanning microscopy image of root tips. Scale bar indicates $50 \mu \mathrm{m}$ in the upper and middle panels and $20 \mu \mathrm{m}$ in the bottom panel.
To confirm that the enhanced Verticillium resistance in mutant A1 is caused by overexpression of AHL19, transgenic lines that constitutively express AHL19 were generated in both Ws and Col-0. To this end, an overexpression construct was generated that contained the AHL19 coding sequence behind the constitutive Cauliflower mosaic virus $35 \mathrm{~S}$ promoter and transformed into Arabidopsis. Interestingly, AHL19-overexpressing plants showed morphological phenotypes similar to those of A1 mutant plants: larger leaf size, delayed flowering, and delayed senescence. Subsequently, the AHL19-overexpressing lines were challenged with $V$. dahliae together with the corresponding wild type and an AHL19 knock-out allele in Ws (ahl19-2). This analysis showed clear Verticillium wilt symptoms on wild-type and ahl19-2 plants from 14 dpi onward that resulted in severe wilting, stunting, and chlorosis by 21 dpi (Fig. 5A and B). In contrast, the overexpression lines remained symptomless. Real-time PCR analysis showed that, whereas the wild-type and knock-out allele accumulated similar levels of $V$. dahliae biomass by $21 \mathrm{dpi}$, significantly less Verticillium biomass was detected in the overexpression lines (Fig. 5C and D). Similar results were observed when Col-0, ahl19-1, and three independent AHL19-overexpressing lines were challenged with $V$. dahliae (Supplementary Fig. S10). Altogether, these data confirm that AHL19 overexpression mediates Verticillium resistance in Arabidopsis.

\section{Transcriptional regulation of $\mathrm{AHL19}$.}

Because constitutive activation of AHL19 is causal to the enhanced Verticillium resistance in the A1 mutant, we assessed AHL19 expression in the A2, A3, and A4 mutants in the absence of pathogen challenge. As expected, this analysis showed that the level of AHL19 transcripts in these mutants was not elevated when compared with wild-type plants and, thus, constitutive activation of AHL19 cannot explain the enhanced Verticillium resistance in the A2, A3, and A4 mutants (Supplementary Fig. S11). Subsequently, the expression level of AHL19 was assessed in roots and shoots of noninoculated WS and A1 mutant plants. Whereas, in wild-type plants, slight AHL19 expression was detected in the roots and no expression was detected in the shoots, A1 plants showed slightly elevated AHL19 expression in the roots and strong expression in the shoots (Fig. 6A), consistent with the finding that Verticillium colonization is contained in the shoots of A1 plants. Furthermore, AHL19 expression was assessed in a time course of $V$. dahliae-inoculated wild-type (Ws) plants with real-time PCR in the shoots. This analysis showed that AHL19 is strongly induced upon $V$. dahliae inoculation, because the level of AHL19 transcripts is nearly 10-fold induced upon 5 min of incubation in a suspension of $V$. dahliae conidiospores when compared with mock inoculation (Fig. 6B). Also, foliar inoculation with B. cinerea conidiospores resulted in a fast induction of AHL19 transcription (Supplementary Fig. S12A). By 7 days post-V. dahliae inoculation, AHL19 transcription was approximately threefold induced and, by $14 \mathrm{dpi}$, the level of AHL19 transcripts was reduced to basal levels (Fig. 6B). A similar repression of AHL19 transcription was observed in V. dahlia-inoculated Col-0 plants.

To further assess the transcriptional regulation of AHL19 in Arabidopsis, the Bio-Array Resource Expression Angler (Toufighi et al. 2005) was queried for AHL19 expression in various microarray studies. This analysis showed that AHL19 is induced in a transient fashion upon inoculation with various pathogens (B. cinerea, Erysiphe orontii, P. syringae, and Phytophthora infestans) and the pathogen-associated molecular pattern flg22. Furthermore, AHL19 expression is induced upon treatment with indole-3-acetic acid (IAA) but not with other plant hormones, including abscissic acid, methyl jasmonate, 
salicylic acid, gibberellic acid, or brassinosteroids (Supplementary Fig. S13). Finally, whereas osmotic and salt stress slightly downregulate AHL19 expression, the gene appears slightly induced upon drought and oxidative stress.

The Arabidopsis genome encodes 29 AT-hook motif nuclear localized DNA-binding proteins (AHL, of which AHL15 and AHL20 are most closely related to AHL19 (Fujimoto et al. 2004). Query of the Bio-Array Resource Expression Angler revealed that $A H L 15$ and $A H L 20$ do not respond as extensively to pathogen attack as AHL19 (Supplementary Fig. S14). Whereas greater than twofold induction of AHL19 expression can be observed upon challenge inoculation with all of the pathogens or flg22, expression of AHL15 and AHL2O is only slightly induced and not by all of the pathogens.

\section{Expression of defense marker genes in the A1 mutant.}

The expression of typical defense marker genes was analyzed in the Ws and A1 mutant plants before and after Verticillium spp. inoculation. The expression of salicylic acid marker gene PRl was low in noninoculated plants and showed a significant induction by 8 dpi in Ws (Supplementary Fig. S15A). In the A1 mutant, no increased PRl expression was observed after inoculation, which may be attributed to the absence of fungal colonization. Interestingly, expression of the jasmonic acid

Table 1. Analysis of the genomic region surrounding the activation tag insertion site in mutant A1

\begin{tabular}{|c|c|c|c|c|}
\hline Gene $^{a}$ & Annotation & Expression $^{b}$ & Knock-out allele & Verticillium dahliae phenotype \\
\hline At3g04520 & Threonine aldolase & Similar & SALK_069973 & Similar \\
\hline At3g04530 & Phosphoenolpyruvate carboxylase kinase 2 & Induced in $\mathrm{A} 1$ & SALK_102132 & Similar \\
\hline At3g04540 & Defensin-like protein & Similar & None available & Not tested \\
\hline At3g04545 & Defensin-like protein & Similar & FLAG_378H04 & Similar \\
\hline At3g04550 & Unknown protein & Similar & SALK_151062C & Similar \\
\hline At3g04560 & Unknown protein & Similar & SALK_110145C & Similar \\
\hline At3g04570 & DNA-binding protein AHL19 & Induced in A1 & SALK_070123C (ahl19-1) & Enhanced susceptibility \\
\hline At3g04580 & Ethylene receptor subfamily & Repressed in A1 & FLAG_322D05 & Similar \\
\hline At3g04590 & DNA-binding family protein & Similar & SALK_081411 & Similar \\
\hline At3g04600 & tRNA synthetase class I (W and Y) family protein & Similar & FLAG_048G11 & Similar \\
\hline At3g04605 & Transposon element & Repressed in A1 & FLAG_404H06 & Similar \\
\hline At3g04610 & RNA binding, nucleic acid binding & Similar & SALK_001523 & Similar \\
\hline At3g04620 & Nucleic acid binding & Similar & SALK_124178C & Similar \\
\hline At3g04630 & KLEEK domain family protein & Repressed in A1 & SALK_020938 & Similar \\
\hline
\end{tabular}

a Gene harboring the activation tag insertion site (At3g04570) is indicated in bold.

${ }^{\mathrm{b}}$ Gene expression in mutant A1 relative to the expression in the wild type.

${ }^{\mathrm{c}}$ Phenotype of knock-out alleles upon $V$. dahliae inoculation when compared with wild-type plants.
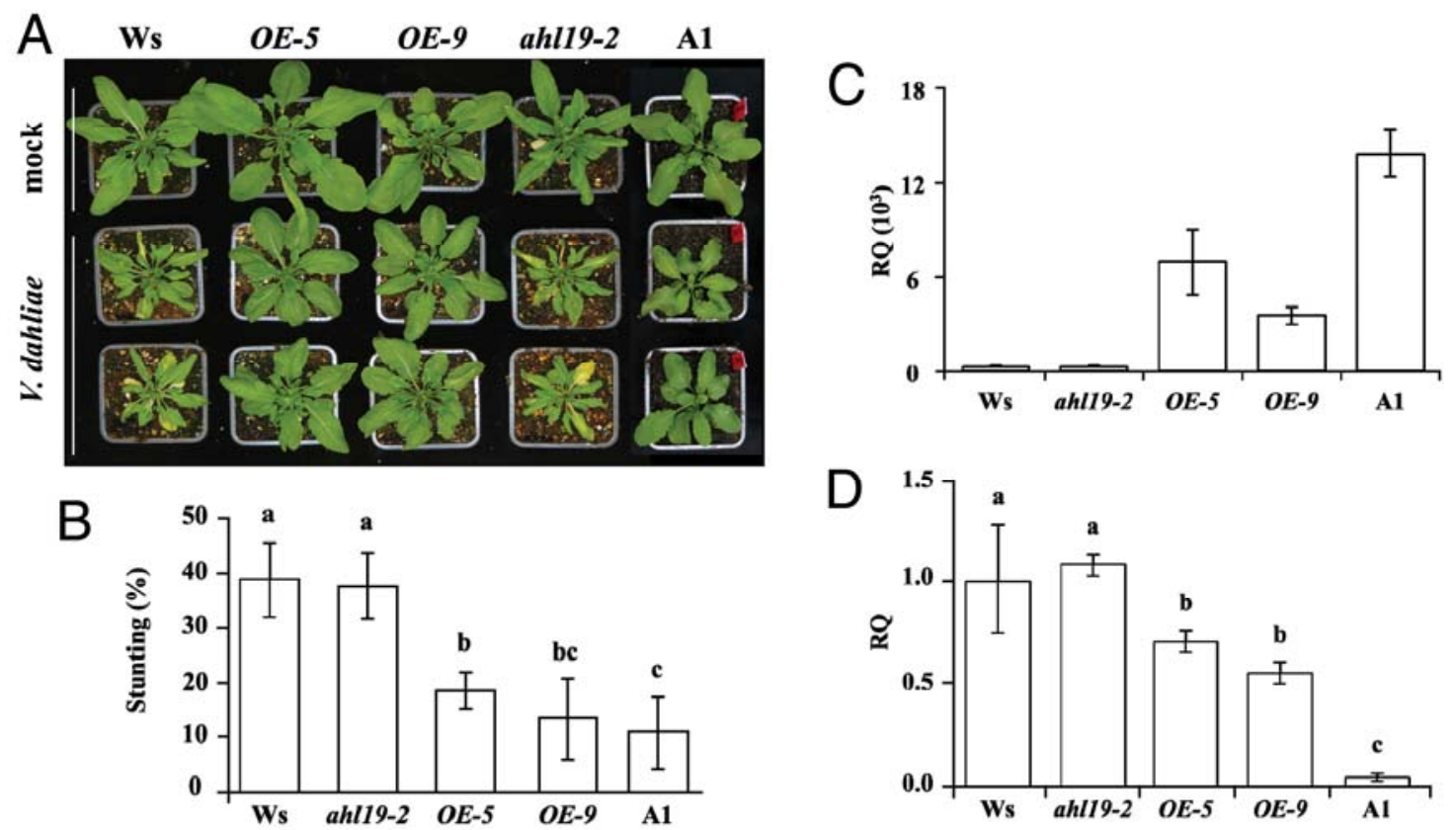

Fig. 5. Overexpression of AHL19 enhances Verticillium dahliae resistance. A, Typical symptoms upon V. dahliae inoculation of wild-type (Ws) plants, plants of the A1 mutant, two independent AHL19 overexpression lines (OE-5 and OE-9), and the AHL19 knockout line (ahl19-2), all in WS background, when compared with mock-inoculated plants at 22 days postinoculation (dpi). A representative of three independent experiments is shown. B, Verticillium spp.induced stunting of wild-type (Ws) plants, plants of the A1 mutant, two independent $A H L 19$ overexpression lines $(O E-5$ and $O E-9)$, and the $A H L 19$ knockout line (ahl19-2) at 22 dpi. Rosette diameters of inoculated plants were compared with those of mock-inoculated plants. Bars represent averages of three independent experiments with standard deviation and letter codes indicate significant differences (Dunnett $t$ test at $P=0.05$ ). C, Relative quantification (RQ) of $A H L 19$ transcription in 4-week-old wild-type (Ws) plants, plants of the A1 mutant, two independent $A H L 19$ overexpression lines (OE-5 and $O E-9)$, and the AHL19 knockout line (ahl19-2). Bars represent averages with standard deviation of three biological replicates. D, RQ by real-time polymerase chain reaction on genomic DNA of $V$. dahliae colonization in wild-type (Ws) plants, plants of the A1 mutant, two independent $A H L 19$ overexpression lines $(O E-5$ and $O E-9)$, and the AHL19 knockout line (ahl19-2) by comparing levels of the $V$. dahliae internal transcribed spacer region of the ribosomal DNA (as measure for fungal biomass) relative to levels of the large subunit of the Arabidopsis RuBisCo gene (for equilibration) at 22 dpi. Bars represent averages with standard deviation of four technical replicates. A representative of three independent experiments is shown. 
marker genes $P D F 1.2$ and $V S P 2$ was enhanced in the noninoculated A1 mutant and expression decreased after inoculation. In WS plants, VSP2 expression follows a similar pattern whereas $P D F 1.2$ expression is induced by Verticillium inoculation. In addition, we investigated the expression of three flg22induced genes (NHO1, FRK1, and WRKY22) in Ws and A1 mutant plants. Verticillium inoculation did not significantly affect $\mathrm{NHOl}$ expression in wild-type and A1 mutant plants. In contrast, FRK1 expression was suppressed in noninoculated A1 mutant plants when compared with noninoculated Ws plants and not influenced by Verticillium inoculation. Finally, WRKK 22 was suppressed in the A1 mutant at 4 dpi and again induced by $8 \mathrm{dpi}$ in the A1 mutant. Overall, the expression analysis does not reveal constitutive defense gene expression that can explain the enhanced resistance phenotype toward Verticillium spp. of the A1 mutant.

\section{DISCUSSION}

In a phenotypic screening for altered susceptibility to $V$. dahliae, we identified four gain-of-function mutants which showed enhanced Verticillium resistance. Interestingly, in all mutants, the enhanced resistance phenotype concerned the three pathogenic Verticillium spp. that are able to infect Arabidopsis: V. dahliae, V. albo-atrum, and V. longisporum. Furthermore, it was found that the enhanced Verticillium resistance was combined with enhanced resistance toward the vascular

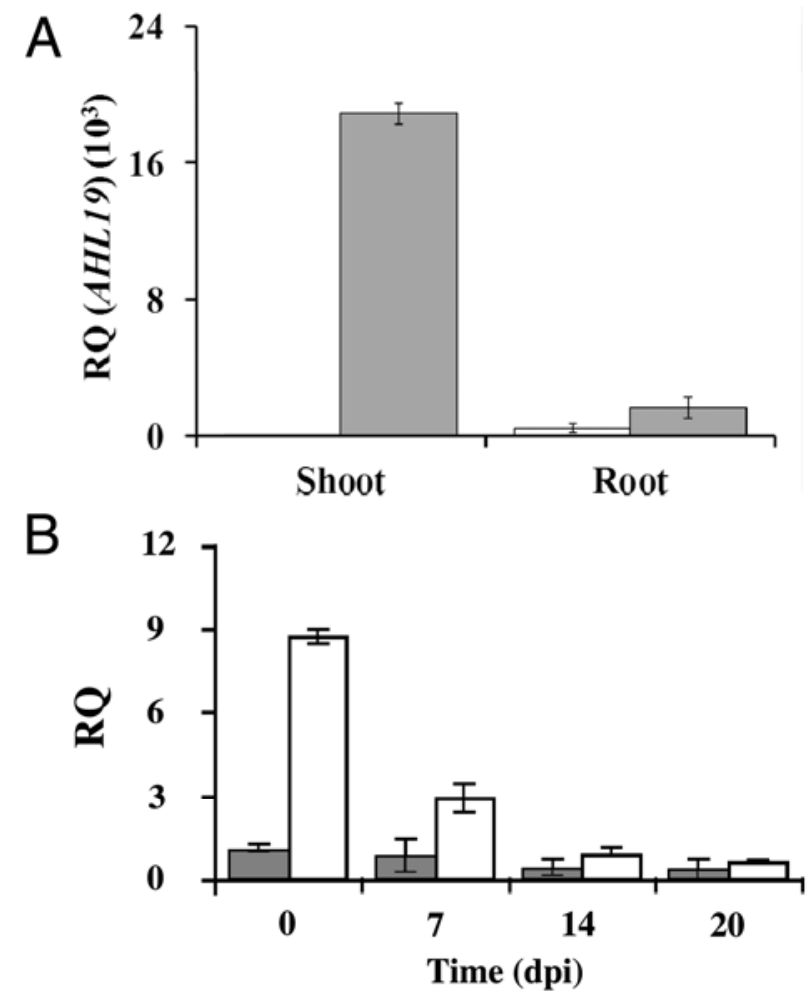

Fig. 6. Expression of AHL19 upon Verticillium dahliae inoculation. A, Relative quantification (RQ) of $A H L 19$ transcription in roots and shoots of noninoculated wild-type (Ws) (white bars) and A1 mutant (gray bars) plants. The AHL19 transcript level in the shoots of Ws is set at 1 and used for calibration. A representative of two independent biological replications is shown and bars indicate averages of three technical replicates with standard deviation. B, RQ of AHL19 transcription in wild-type (Ws) plants immediately upon inoculation (0) and at 7,14 , and 20 days post- $V$. dahliae (white bars) or mock (gray bars) inoculation is shown. The AHL19 transcript level of mock inoculation at $0 \mathrm{dpi}$ is set at 1 and used for calibration. Bars represent averages with standard deviation of three independent biological replicates. bacterial pathogen $R$. solanacearum in the A2 mutant, and with enhanced susceptibility toward the foliar bacterial pathogen Pseudomonas syringae in the A1 and A3 mutants. Remarkably, enhanced resistance toward the vascular fungus $F$. oxysporum was obtained in none of the mutants, despite the fact that $F$. $o x$ ysporum shares important features with respect to biology and infection style with Verticillium spp. (Klosterman et al. 2011).

In this study, we pursued cloning of the activation tag insertion site in the A1 mutant. Interestingly, of the 14 genes that were identified in a $30-\mathrm{kb}$ window surrounding the activation tag insertion site, only two genes were induced in the A1 mutant whereas three genes were repressed when compared with the expression in wild-type plants. Analysis of knock-out alleles of nearly all genes showed that an insertion in only one of the induced genes, AHL19, resulted in enhanced Verticillium susceptibility. Thus, the enhanced resistance can be attributed to overexpression of the AHL19 gene. Activation of AHL19 was observed in none of the other activation tagging mutants (A2, A3, and A4). Altogether, these findings demonstrate that the four mutants are not allelic, and the cloning of the insertion sites in the other mutations will be reported in future manuscripts.

AHL19 encodes a predicted AT-hook DNA-binding protein. The AT-hook is a positively charged 13 -amino-acid motif centered on a glycin-arginine-proline tripeptide that is necessary and sufficient to bind DNA and that is flanked by basic residues (Aravind and Landsman 1998; Huth et al. 1997; Reeves and Nissen 1990). The motif was initially described in the high-mobility group non-histone chromosomal proteins but later widely identified in single or multiple copies in DNAbinding proteins, many of which are transcription factors or components of chromatin remodeling complexes, from various organisms (Aravind and Landsman 1998; Reeves and Nissen 1990). In plants, the AT-hook motif was found in nuclear matrix proteins that bind to the so-called matrix attachment regions of chromosomal DNA (Fujimoto et al. 2004; Morisawa et al. 2000). In general, the AT-hook motif binds to the minor groove of DNA, changes the DNA architecture, and alters gene expression (Aravind and Landsman 1998; Fujimoto et al. 2004; Lim et al. 2007; Matsushita et al. 2007; Xiao et al. 2009).

The Arabidopsis genome encodes 29 AHL that, in addition to the AT-hook motif, contain a conserved hydrophobic plant and prokaryote conserved domain which is responsible for nuclear localization (Fujimoto et al. 2004). Interestingly, several AHL proteins have been reported to regulate plant development. Whereas ESC/AHL27, SOB3/AHL29, and AHL22 all negatively regulate hypocotyl growth (Lim et al. 2007; Street et al. 2008; Xiao et al. 2009), overexpression of AHL27 delays senescence and increases the postharvest storage life of plants (Lim et al. 2007), overexpression of SOB3/AHL29 increased leaf and flower size, and overexpression of $A H L 22$ causes late flowering (Xiao et al. 2009). As observed in our study, AHL19-overexpressing plants also gained similar developmental characteristics, including increased rosette leaf size and delayed maturity. This suggests that AHL19, like other members of the AT-hook DNA-binding protein family, regulates plant development.

\section{AHL19 regulates Verticillium resistance.}

We have shown that overexpression of AHL19 in Ws and Col-0 plants resulted in robust Verticillium resistance. Furthermore, the T-DNA insertion line in Col-0 (ahl19-1) displayed clearly enhanced Verticillium susceptibility. The observation that a T-DNA insertion in the Ws allele (ahl19-2) did not result in enhanced susceptibility may be explained by the fact that the susceptibility of the Ws ecotype is already high when compared with the Col-0 ecotype and, thus, a further enhancement of susceptibility may remain unnoticed. 
Interestingly, our data show that resistance to Verticillium spp. is not obtained in the roots but, rather, in the shoots of the A1 mutant. Fungal presence was clearly detected in aboveground plant organs, revealing that the fungus is able to enter the xylem vessels and is not contained in the roots. Moreover, AHL19 appeared to be especially overexpressed in the shoots of the A1 mutant. The finding that Verticillium resistance is only established once the fungus has entered the xylem vessels is typical for the physiology of Verticillium resistance in other plant species as well. Also, in tomato lines that harbor the Ve1 resistance gene, incompatible fungal strains enter the vascular system after root penetration, and resistance is only established after the fungus has started to colonize the plant, leading to elimination of the fungus (Chen et al. 2004; Fradin et al. 2009, 2011; Gold and Robb 1995; Heinz et al. 1998).

To study how AHL19 is regulated during Verticillium infection, we analyzed the expression of AHL19 in the wild-type plant after inoculation with Verticillium spp. The real-time PCR analyses of time-course experiments suggested that the fungus attempts to suppress AHL19 expression. AHL19 transcription is activated immediately upon $V$. dahliae inoculation, because the level of AHL19 transcripts is nearly 10-fold induced upon $5 \mathrm{~min}$ of incubation in a suspension of $V$. dahliae conidiospores when compared with mock inoculation. The immediate activation of AHL19 upon pathogen presence and targeting of its expression by the pathogen further substantiates a crucial role for AHL19 in the activation of host defense against pathogens.

Until recently, AHL proteins have not been implicated in plant defense against pathogens. In chili pepper (Capsicum annuum), the AT-hook DNA-binding protein-encoding gene CaATL1 was specifically induced upon pathogen inoculation. Transgenic tomato plants overexpressing CaATL1 showed enhanced resistance against $P$. syringae and Phytophthora capsici (Kim et al. 2007). Furthermore, whereas, in this study, we characterized AHL19 as a positive regulator of fungal defense, recently the close relative AHL20 was characterized as a negative regulator of plant immunity. Overexpression of AHL2O in Arabidopsis followed by treatment with the flg22 peptide that is derived from bacterial flagellin was found to suppress expression of $\mathrm{NHOl}$, a gene that encodes a glycerol kinase that is required for bacterial immunity (Kang et al. 2003; Lu et al. 2001), and resulted in enhanced susceptibility toward Pseudomonas syringae (Lu et al. 2010). Furthermore, transient expression of $A H L 2 O$ in protoplasts abolished flg22-induced expression of the flagellin-induced receptor kinase FRK1 (Asai et al. 2002; Lu et al. 2010). However, these studies solely relied on overexpression and a detailed genetic analysis including knock-out alleles has not been performed (Kim et al. 2007; Lu et al. 2010). Here, we have provided a thorough genetic and phytopathological study to implicate AHL19 as a positive regulator of defense against Verticillium infection. The expression analysis suggests that AHL19 and AHL2O do not act redundantly, because $A H L 19$ is generally induced by pathogen attack while $A H L 2 O$ and, also, the closely related $A H L 15$ are only moderately pathogen induced. The major challenge will now be to determine how AHL19 regulates pathogen defense. Although expression of the jasmonate signaling marker genes $P D F 1.2$ and VSP2 was found to be enhanced in noninoculated A1 plants, it is unlikely that constitutive jasmonate-mediated defenses can account for the enhanced resistance in the A1 mutant. First, as suggested by the marker gene expression levels and the lack of enhanced resistance toward the foliar necrotrophic pathogens B. cinerea and Plectosphaerella cucumerina that are typically contained by jasmonate-mediated defenses (Thomma et al. 1998, 2001), the level of enhanced jasmonatemediated defenses is likely too low to actually achieve en- hanced pathogen resistance. Second, several studies have indicated that basal defense toward Verticillium spp. in Arabidopsis is not governed by jasmonate or salicylic acid signaling (Fradin et al. 2011; Johansson et al. 2006; Pantelides et al. 2010; Veronese et al. 2003). Finally, other than by IAA, AHL19 expression does not appear to be induced by defense-related hormones.

\section{MATERIALS AND METHODS}

\section{Cultivation of plants and microorganisms.}

Arabidopsis thaliana plants were soil-grown in either the greenhouse or a growth chamber. In the greenhouse, the conditions were 21 and $19^{\circ} \mathrm{C}$ during the 16-h day and 8-h night period, respectively; $70 \%$ relative humidity $(\mathrm{RH})$; and $100 \mathrm{~W} / \mathrm{m}^{2}$ supplemental light when the intensity dropped below 150 $\mathrm{W} / \mathrm{m}^{2}$. In the climate chamber, the conditions were 21 and $19^{\circ} \mathrm{C}$ during the $14-\mathrm{h}$ day and 10 -h night period, respectively; $70 \% \mathrm{RH}$; and a light intensity of $150 \mathrm{~W} / \mathrm{m}^{2}$.

Verticillium spp. and Alternaria brassicicola were cultivated on potato dextrose agar, $B$. cinerea and $P$. cucumerina on malt extract agar, and $F$. oxysporum f. sp. raphani on Czapek-Dox agar, all at room temperature. Pseudomonas syringae pv. tomato DC3000 and $R$. solanacearum strains were cultivated as described (Deslandes et al. 1998; van Esse et al. 2008).

\section{Pathogen inoculations.}

Verticillium inoculations were performed as previously described (Ellendorff et al. 2009; van Esse et al. 2008) with the modification that roots were dipped in the conidial suspension for $5 \mathrm{~min}$. F. oxysporum f. sp. raphani budcell inoculum was prepared as described (Diener and Ausubel 2005), and inoculation was performed as with Verticillium spp. Inoculations with B. cinerea, Plectosphaerella cucumerina (both at $10^{6}$ conidia/ $\mathrm{ml}$ ), and Pseudomonas syringae p. v. tomato DC3000 were performed as previously described (van Esse et al. 2008). A. brassicicola was inoculated as with Plectosphaerella cucumerina. At 3 and 5 dpi, pictures were taken of all inoculated plants and lesion diameters were measured using ImageJ software. Inoculation with $R$. solanacearum was performed as described (Deslandes et al. 1998).

\section{Assessment of root development.}

Arabidopsis was grown in vitro on half-strength Murashige and Skoog medium supplemented with $0.5 \%$ sucrose and solidified with $1.2 \%$ plant agar. Prior to sowing, seed were surface sterilized using $40 \%$ sodium hypochlorite containing $3 \mathrm{ml}$ of hydrochloric acid (37\%) for $4 \mathrm{~h}$. After sowing, plates were incubated at $4^{\circ} \mathrm{C}$ for 4 days and subsequently transferred to the growth chamber and incubated vertically. At 2 weeks postgermination, roots of the wild-type and activation-tagged mutants were examined using a microscope.

For microscopic analysis, root sections (approximately 1 $\mathrm{cm}$ ) harvested from 2-week-old plants were fixed in $0.1 \mathrm{M}$ phosphate buffer ( $\mathrm{pH} 7.2$ ), $2.5 \%$ glutaraldehyde, and $4 \%$ paraformaldehyde for $1 \mathrm{~h}$. After rinsing in $0.1 \mathrm{M}$ phosphate buffer (15 $\mathrm{min})$ and distilled water $(15 \mathrm{~min})$, the root sections were dehydrated by successive incubation for $20 \mathrm{~min}$ in $10,30,50$, 70,90 , and $100 \%$ ethanol. Subsequently, the pieces were successively incubated for $1 \mathrm{~h}$ in 25,50 , and $75 \%$ presolution $\mathrm{A}$ (100 ml of technovit 7100 [Heraeaus Kulzer, Wehrheim, Germany], a packet of Hardener I, and $2.5 \mathrm{ml}$ of polyethylene glycol 400) in ethanol, followed by overnight incubation in $100 \%$ presolution A at room temperature. Subsequently, the root sections were embedded in mold using polymerization solution (presolution A and Hardener II, 15:1 vol/vol), glued to a block with technovit 3040, and sectioned using a microtome. The 
section was stained with toluidine blue and observed under a microscope.

For confocal laser-scanning microscopy, the roots were fixed and stained (Truernit et al. 2008). A Zeiss LSM ConfoCor 2 microscope was used. The samples were imaged through a C-Apochromat 40xW. The pinhole was adjusted to a Z-depth of $1.5 \mu \mathrm{m}$. The excitation wavelength for the propidium iodide stained samples was $543 \mathrm{~nm}$ using an HeNe laser and the fluorescence was filtered by a $560-\mathrm{nm}$ long pass.

\section{Determination of the activation tag insertion site.}

TAIL-PCR was performed as described (Terauchi and Kahl 2000) with a combination of nested primers (Marsch-Martinez et al. 2002) and 10-mer random primers (Terauchi and Kahl 2000). The secondary and tertiary TAIL-PCR were separated on $1.2 \%$ agarose gel, stained with ethidium bromide, and visualized using the ChemiDoc XRS system (Bio-Rad, Munich). Specific product, judged based on the size differences generated by the nested primers, was excised, cleaned using the QIAquick gel extraction kit (Qiagen, Hilden, Germany), cloned into the pGEM-T Easy vector (Invitrogen), and sequenced. BlastN search of the TAIR database was used to identify the genomic insertion site. Based on the putative insertion site in AHL19, primers DBPR-F1 and DBPR-R1 (Supplementary Table S1) were designed to amplify the flanking region. By sequencing this region in the wild type and the mutant, the exact position of the activation tag insertion was identified.

\section{AHL19 overexpression.}

The AHL19 CDS was amplified with primers AHL19-BaF and AHL19-AsR, which include BamHI and AscI restriction sites, respectively, using $P f u$ DNA polymerase (Promega, Madison, WI, U.S.A.). The amplicon was cloned into the BamHI- and AscI-digested binary vector pB7k40, a variant of vector pB7WG2 (Karimi et al. 2002), where the sequences between KpnI and SacI (which include the $35 \mathrm{~S}$ promoter and terminator) were replaced with sequences between $K p n I$ and $S a c I$ (35S promoter, multiple cloning site, and terminator from potato proteinase inhibitor II-PiII) of a pmog800 variant (Fradin et al. 2009). The resulting vector was checked by sequencing. Subsequently, the construct was transformed into Agrobacterium tumefaciens GV3101 and transformed into Arabidopsis (Clough and Bent 1998). All assays were performed with T2 generation transgenes, and transgene presence was confirmed for each individual plant by PCR. AHL19 expression was assessed with real-time PCR using an ABI7300 PCR machine (Applied Biosystems) in combination with the qPCR Core kit for SYBR Green I (Eurogentec, Maastricht, The Netherlands) and analyzed using the 7300 System SDS software (Applied Biosystems, Foster City, CA, U.S.A.). The Arabidopsis actin 2 gene primer pair, Act2-F and Act2-R, was used as endogenous control and the primer pair DBP-F1 and DBP-R1 was used for quantification of AHL19 transcript levels. Real-time PCR conditions consisted of $2 \mathrm{~min}$ of incubation at $50^{\circ} \mathrm{C}$ and 10 min at $95^{\circ} \mathrm{C}$, followed by 40 cycles of $95^{\circ} \mathrm{C}$ for $15 \mathrm{~s}$ and $60^{\circ} \mathrm{C}$ for $1 \mathrm{~min}$.

\section{Expression of defense markers.}

For expression analysis of defense marker genes, mock-and V. dahliae-inoculated Ws and A1 mutant plants were harvested prior to inoculation and at 4 and 8 dpi. Subsequently, total RNA was extracted using the NucleoSpin RNA Plant kit (Machery-Nagel, Leiden, The Netherlands) and cDNA was synthesized as previously described (Ellendorff et al. 2009). Real-time PCR was performed using target gene primers and the Arabidopsis actin 2 gene primer as endogenous control.
Real-time PCR conditions consisted of 2 min of incubation at $50^{\circ} \mathrm{C}$ and $10 \mathrm{~min}$ at $95^{\circ} \mathrm{C}$, followed by 40 cycles of $95^{\circ} \mathrm{C}$ for $15 \mathrm{~s}$ and $60^{\circ} \mathrm{C}$ for $1 \mathrm{~min}$.

\section{Pathogen quantification in planta.}

Real-time PCR on genomic DNA was used for quantification of pathogen colonization in planta using an ABI7300 PCR machine (Applied Biosystems) in combination with the qPCR Core kit for SYBR Green I (Eurogentec) and analyzed using the 7300 System SDS software (Applied Biosystems). Unless described otherwise, the primer pair AtRub-F4 and AtRub-R4 targeting the gene encoding the large subunit of RuBisCo was used as endogenous control. Verticillium colonization was assessed as described in Ellendorff and associates (2009). For Pseudomonas syringae and $R$. solanacearum colonization, at least three inoculated plants were harvested at 3 and 5 dpi and DNA was isolated (Fulton et al. 1995). The primer pair Pstq-F and Pstq-R was used to target $P$. syringae, while the primer pair R.solF and R.solR was used to target $R$. solanacearum (Brouwer et al. 2003; Huang et al. 2009).

\section{ACKNOWLEDGMENTS}

This research is supported by the Dutch Technology Foundation STW, which is the applied science division of NWO, and the Technology Programme of the Ministry of Economic Affairs. B. P. H. J. Thomma is supported by a Vidi grant of the Research Council for Earth and Life sciences (ALW) of the Netherlands Organization for Scientific Research (NWO). We thank A. Aharoni, S. van Broekhoven, M. W. Jalata, N. MarschMartinez, and N. de Ruijter for technical assistance; and H. Smid and B. Essenstam for excellent plant care.

\section{LITERATURE CITED}

Aboul-Soud, M. A. M., Chen, X., Kang, J. G., Yun, B. W., Raja, M. U., Malik, S. I., and Loake, G. J. 2009. Activation tagging of ADR2 conveys a spreading lesion phenotype and resistance to biotrophic pathogens. New Phytol. 183:1163-1175.

Aravind, L., and Landsman, D. 1998. AT-hook motifs identified in a wide variety of DNA-binding proteins. Nucleic Acids Res. 26:4413-4421.

Asai, T., Tena, G., Plotnikova, J., Willmann, M. R., Chiu, W. L., GomezGomez, L., Boller, T., Ausubel, F. M., and Sheen, J. 2002. Map kinase signalling cascade in Arabidopsis innate immunity. Nature 415:977-983.

Ayliffe, M. A., and Pryor, A. J. 2007. Activation tagging in plants-generation of novel, gain-of-function mutations. Aust. J. Agric. Res. 58:490-497.

Brouwer, M., Lievens, B., Van Hemelrijck, W., van den Ackerveken, G., Cammue, B. P. A., and Thomma, B. P. H. J. 2003. Quantification of disease progression of several microbial pathogens on Arabidopsis thaliana using real-time fluorescence PCR. FEMS (Fed. Eur. Microbiol. Soc.) Microbiol. Lett. 228:241-248.

Chen, P., Lee, B., and Robb, J. 2004. Tolerance to a non-host isolate of Verticillium dahliae in tomato. Physiol. Mol. Plant. Pathol. 64:283-291.

Clough, S. J., and Bent, A. F. 1998. Floral dip: A simplified method for Agrobacterium-mediated transformation of Arabidopsis thaliana. Plant J. 16:735-743.

Deslandes, L., Pileur, F., Liaubet, L., Camut, S., Can, C., Williams, K., Holub, E., Beynon, J., Arlat, M., and Marco, Y. 1998. Genetic characterization of RRS1, a recessive locus in Arabidopsis thaliana that confers resistance to the bacterial soilborne pathogen Ralstonia solanacearum. Mol. Plant-Microbe Interact. 11:659-667.

Diener, A. C., and Ausubel, F. M. 2005. RESISTANCE TO FUSARIUM OXYSPORUM 1, a dominant Arabidopsis disease-resistance gene, is not race specific. Genetics 171:305-321.

Ellendorff, U., Fradin, E. F., de Jonge, R., and Thomma, B. P. H. J. 2009. RNA silencing is required for Arabidopsis defence against Verticillium wilt disease. J. Exp. Bot. 60:591-602.

Fradin, E. F., and Thomma, B. P. H. J. 2006. Physiology and molecular aspects of Verticillium wilt diseases caused by $V$. dahliae and $V$. alboatrum. Mol. Plant Pathol. 7:71-86.

Fradin, E. F., Zhang, Z., Ayala, J. C. J., Castroverde, C. D. M., Nazar, R. N., Robb, J., Liu, C. M., and Thomma, B. P. H. J. 2009. Genetic dissection of Verticillium wilt resistance mediated by tomato Vel. Plant Physiol. 150:320-332.

Fradin, E. F., Abd-El-Haliem, A., Masini, L., van den Berg, G. C. M., 
Joosten, M. H. A. J., and Thomma, B. P. H. J. 2011. Interfamily transfer of tomato Ve1 mediates Verticillium resistance in Arabidopsis. Plant Physiol. 156:2255-2265.

Fujimoto, S., Matsunaga, S., Yonemura, M., Uchiyama, S., Azuma, T., and Fukui, K. 2004. Identification of a novel plant MAR DNA binding protein localized on chromosomal surfaces. Plant Mol. Biol. 56:225-239.

Fulton, T. M., Chunwongse, J., and Tanksley, S. D. 1995. Microprep protocol for extraction of DNA from tomato and other herbaceous plants. Plant Mol. Biol. Rep. 13:207-209.

Genin, S., and Boucher, C. 2002. Ralstonia solanacearum: Secrets of a major pathogen unveiled by analysis of its genome. Mol. Plant Pathol. 3:111-118.

Gold, J., and Robb, J. 1995. The role of the coating response in Craigella tomatoes infected with Verticillium dahliae, races 1 and 2. Physiol. Mol. Plant Pathol. 47:141-157.

Grant, J. J., Chini, A., Basu, D., and Loake, G. J. 2003. Targeted activation tagging of the Arabidopsis NBS-LRR gene, ADR1, conveys resistance to virulent pathogens. Mol. Plant-Microbe Interact. 16:669-680.

Heinz, R., Lee, S. W., Saparno, A., Nazar, R. N., and Robb, J. 1998. Cyclical systemic colonization in Verticillium-infected tomato. Physiol. Mol. Plant. Pathol. 52:385-396.

Huang, J., Wu, J., Li, C., Xiao, C., and Wang, G. 2009. Specific and sensitive detection of Ralstonia solanacearum in soil with quantitative, realtime PCR assays. J. Appl. Microbiol. 107:1729-1739.

Huth, J. R., Bewley, C. A., Nissen, M. S., Evans, J. N. S., Reeves, R., Gronenborn, A. M., and Clore, G. M. 1997. The solution structure of an HMG-I(Y)-DNA complex defines a new architectural minor groove binding motif. Nat. Struct. Biol. 4:657-665.

Jiang, F., Zhao, J., Zhou, L., Guo, W. Z., and Zhang, T. Z. 2009. Molecular mapping of Verticillium wilt resistance QTL clustered on chromosomes D7 and D9 in upland cotton. Sci. China Ser. C Life Sci. 52:872-884.

Johansson, A., Staal, J., and Dixelius, C. 2006. Early responses in the Arabidopsis-Verticillium longisporum pathosystem are dependent on NDR1, JA- and ET-associated signals via cytosolic NPR1 and RFO1. Mol. Plant-Microbe Interact. 19, 958-969.

Kang, L., Li, J., Zhao, T., Xiao, F., Tang, X., Thilmony, R., He, S., and Zhou, J.M. 2003. Interplay of the Arabidopsis nonhost resistance gene NHO1 with bacterial virulence. Proc. Natl. Acad. Sci. U.S.A. 100:35193524.

Karimi, M., Inzé, D., and Depicker, A. 2002. GATEWAY vectors for Agrobacterium-mediated plant transformation. Trends Plant Sci. 7:193-195.

Kawchuk, L. M., Hachey, J., Lynch, D. R., Kulcsar, F., van Rooijen, G., Waterer, D. R., Robertson, A., Kokko, E., Byers, R., Howard, R. J., Fischer, R., and Prüfer, D. 2001. Tomato Ve disease resistance genes encode cell surface-like receptors. Proc. Natl. Acad. Sci. U.S.A. 98:65116515

Kim, S. Y., Kim, Y. C., Seong, E. S., Lee, Y. H., Park, J. M., and Choi, D. 2007. The chili pepper CaATL1: An AT-hook motif-containing transcription factor implicated in defence responses against pathogens. Mol. Plant Pathol. 8:761-771.

Klosterman, S. J., Atallah, Z. K., Vallad, G. E., and Subbarao, K. V. 2009. Diversity, pathogenicity, and management of Verticillium species. Annu. Rev. Phytopathol. 47:39-62.

Klosterman, S. J., Subbarao, K. V., Kang, S., Veronese, P., Gold, S. E., Thomma, B. P. H. J., Chen, Z., Henrissat, B., Lee, Y.-H., Park, J., GarciaPedrajas, M. D., Barbara, D. J., Anchieta, A., de Jonge, R., Santhanam, P., Maruthachalam, K., Atallah, Z., Amyotte, S. G., Paz, Z., Inderbitzin, P., Hayes, R. J., Heiman, D. I., Young, S., Zeng, Q., Engels, R., Galagan, J., Cuomo, C., Dobinson, K. F., and Ma, L. J. 2011. Comparative genomics yields insights into niche adaptation of plant vascular wilt pathogens. PLoS Pathog. 7:e1002137.

Lim, P. O., Kim, Y., Breeze, E., Koo, J. C., Woo, H. R., Ryu, J. S., Park, D. H., Beynon, J., Tabrett, A., Buchanan-Wollaston, V., and Nam, H. G. 2007. Overexpression of a chromatin architecture-controlling AT-hook protein extends leaf longevity and increases the post-harvest storage life of plants. Plant J. 52:1140-1153.

Liu, Y. G., and Whittier, R. F. 1995. Thermal asymmetric interlaced PCR: Automatable amplification and sequencing of insert end fragments from P1 and YAC clones for chromosome walking. Genomics 25:674-681.

Lu, H., Zou, Y., and Feng, N. 2010. Overexpression of AHL20 negatively regulates defenses in Arabidopsis. J. Integr. Plant Biol. 52:801-808.

Lu, M., Tang, X., and Zhou, J. M. 2001. Arabidopsis NHO1 is required for general resistance against Pseudomonas bacteria. Plant Cell 13:437-447.

Marsch-Martinez, N., Greco, R., Van Arkel, G., Herrera-Estrella, L., and Pereira, A. 2002. Activation tagging using the En-I maize transposon system in Arabidopsis. Plant Physiol. 129:1544-1556.

Matsushita, A., Furumoto, T., Ishida, S., and Takahashi, Y. 2007. AGF1, an
AT-hook protein, is necessary for the negative feedback of AtGA3ox encoding GA 3-oxidase. Plant Physiol. 143:1152-1162.

Morisawa, G., Han-Yama, A., Moda, I., Tamai, A., Iwabuchi, M., and Meshi, T. 2000. AHM1, a novel type of nuclear matrix-localized, MAR binding protein with a single AT hook and a J domain-homologous region. Plant Cell 12:1903-1916.

Pantelides, I. S., Tjamos, S. E., and Paplomatas, E. J. 2010. Ethylene perception via ETR1 is required in Arabidopsis infection by Verticillium dahliae. Mol. Plant Pathol. 11:191-202.

Reeves, R., and Nissen, M. S. 1990. The A.T-DNA-binding domain of mammalian high mobility group I chromosomal proteins. A novel peptide motif for recognizing DNA structure. J. Biol. Chem. 265:8573-8582.

Rowe, R. C., Davis, J. R., Powelson, M. L., and Rouse, D. I. 1987. Potato early dying-causal agents and management strategies. Plant Dis. 71:482-489.

Rygulla, W., Snowdon, R. J., Friedt, W., Happstadius, I., Cheung, W. Y., and Chen, D. 2008. Identification of quantitative trait loci for resistance against Verticillium longisporum in oilseed rape (Brassica napus). Phytopathology 98:215-221.

Schaible, L., Cannon, O. S., and Waddoups, V. 1951. Inheritance of resistance to Verticillium wilt in a tomato cross. Phytopathology 41:986-990.

Simko, I., Haynes, K. G., Ewing, E. E., Costanzo, S., Christ, B. J., and Jones, R. W. 2004. Mapping genes for resistance to Verticillium alboatrum in tetraploid and diploid potato populations using haplotype association tests and genetic linkage analysis. Mol. Gen. Genomics 271:522-531.

Street, I. H., Shah, P. K., Smith, A. M., Avery, N., and Neff, M. M. 2008. The AT-hook-containing proteins SOB3/AHL29 and ESC/AHL27 are negative modulators of hypocotyl growth in Arabidopsis. Plant J. 54:114

Terauchi, R., and Kahl, G. 2000. Rapid isolation of promoter sequences by TAIL-PCR: The 5'-flanking regions of $\mathrm{Pal}$ and $\mathrm{Pgi}$ genes from yams (Dioscorea). Mol. Gen. Genet. 263:554-560.

Thomma, B. P. H. J., Eggermont, K., Penninckx, I. A. M. A., Mauch-Mani, B., Vogelsang, R., Cammue, B. P. A., and Broekaert, W. F. 1998. Separate jasmonate-dependent and salicylate-dependent defense-response pathways in Arabidopsis are essential for resistance to distinct microbial pathogens. Proc. Natl. Acad. Sci. U.S.A. 95:15107-15111

Thomma, B. P. H. J., Penninckx, I. A. M. A., Broekaert, W. F., and Cammue, B. P. A. 2001. The complexity of disease signaling in Arabidopsis. Curr Opin. Immunol. 13:63-68.

Thomma, B. P. H. J., Cammue, B. P. A., and Thevissen, K. 2002. Plant defensins. Planta 216:193-202.

Tjamos, S. E., Flemetakis, E., Paplomatas, E. J., and Katinakis, P. 2005. Induction of resistance to Verticillium dahliae in Arabidopsis thaliana by the biocontrol agent K-165 and pathogenesis-related proteins gene expression. Mol. Plant-Microbe Interact. 18:555-561.

Toufighi, K., Brady, S. M., Austin, R., Ly, E., and Provart, N. J. 2005. The Botany Array Resource: e-Northerns, Expression Angling, and promoter analysis. Plant J. 43:153-163

Truernit, E., Bauby, H., Dubreucq, B., Grandjean, O., Runions, J., Barthélémy, J., and Palauqui, J.-C. 2008. High-resolution whole-mount imaging of three-dimensional tissue organization and gene expression enables the study of phloem development and structure in Arabidopsis. Plant Cell 20:1494-1503.

van Esse, H. P., van 't Klooster, J. W., Bolton, M. D., Yadeta, K. A., van Baarlen, P., Boeren, S., Vervoort, J., de Wit, P. J. G. M., and Thomma, B. P. H. J. 2008. The Cladosporium fulvum virulence protein Avr2 inhibits host proteases required for basal defense. Plant Cell 20:1948-1963.

Veronese, P., Narasimhan, M. L., Stevenson, R. A., Zhu, J. K., Weller, S. C., Subbarao, K. V., and Bressan, R. A. 2003. Identification of a locus controlling Verticillium disease symptom response in Arabidopsis thaliana. Plant J. 35:574-587.

Weigel, D., Ahn, J. H., Blázquez, M. A., Borevitz, J. O., Christensen, S. K., Fankhauser, C., Ferrándiz, C., Kardailsky, I., Malancharuvil, E.J., Neff, M. M., Nguyen, J. T., Sato, S., Wang, Z. Y., Xia, Y., Dixon, R.A., Harrison, M. J., Lamb, C. J., Yanofsky, M. F., and Chory, J. 2000. Activation tagging in Arabidopsis. Plant Physiol. 122:1003-1013.

Wilhelm, S. 1955. Longevity of the Verticillium wilt fungus in the laboratory and in the field. Phytopathology 45:180-181.

Xia, Y., Suzuki, H., Borevitz, J., Blount, J., Guo, Z., Patel, K., Dixon, R. A., and Lamb, C. 2004. An extracellular aspartic protease functions in Arabidopsis disease resistance signaling. EMBO (Eur. Mol. Biol. Organ.) J. 23:980-988.

Xiao, C., Chen, F., Yu, X., Lin, C., and Fu, Y. F. 2009. Over-expression of an AT-hook gene, AHL22, delays flowering and inhibits the elongation of the hypocotyl in Arabidopsis thaliana. Plant Mol. Biol. 71:39-50. 